\title{
Effects of amlodipine administration and withdrawal on rat pituitary gonadotropins
}

\author{
Latif R \\ Department of Physiology, College of Medicine, University of Dammam, Dammam, Saudi Arabia. \\ dr.rabialatif@gmail.com
}

\begin{abstract}
Objective: The study was aimed to observe the effect of amlodipine on rat pituitary gonadotropins after amlodipine administration and withdrawal.

Methods: It was an experimental study done at Army Medical College, National University of Sciences and Technology, Islamabad, Pakistan from 2009-2010. Sixty adult male rats were divided into groups A and B. Each group was further subdivided into two subgroups of 15 rats each; A1 (control), A2 (control recovery), B1 (amlodipine-treated) and B2 (amlodipine recovery). Amlodipine, $0.04 \mathrm{mg} / \mathrm{kg}$ body weight daily for fifty days was given by means of gavage to groups B1 and B2. Groups A1 and A2 were given vehicle $(0.5 \mathrm{ml}$ distilled water). After 50 days, rats in groups A1 and B1 were sacrificed and their serum LH and FSH levels were measured by Enzyme Immunoassay method. Vehicle and amlodipine were withdrawn in groups A2 and B2, respectively, and the rats were left for recovery to take place for another fifty days. The above procedure was adopted for the measurement of $\mathrm{LH}$ and $\mathrm{FSH}$ levels in the recovered rats.

Results: Amlodipine administration for 50 days resulted in a significant rise in serum LH $(p<0.01)$ whereas serum FSH remained unchanged $(p \geq 0.05)$. Serum LH in amlodipine-treated rats returned to normal after amlodipine withdrawal $(p \geq 0.05)$.

Conclusion: Amlodipine causes a reversible increase in serum LH but it has no effect on serum FSH (Fig. 2,

Ref. 17). Text in PDF www.elis.sk.

Key words: amlodipine, LH, FSH, Sprague Dawley rats, pituitary gonadotropins.
\end{abstract}

The exact mechanism of how amlodipine, a dihydropyridine $\mathrm{CCB}$, causes infertility is still not completely elucidated, thus, further study in this area is needed. Amlodipine has been shown to decrease sperm count in sperm suspensions collected from cauda epididymis of rats (Almaida et al, 2000). In humans, long-term treatment with amlodipine resulted in azoospermia in semen and a few non-motile sperms in testicular sperm extraction (Meacham, 2006). Almaida et al reported a decrease in levels of serum testosterone and FSH but normal LH in prepubertal male rats exposed to amlodipine for one month (Almaida et al, 2000). Previous experiments from our laboratory showed that amlodipine ingestion for 50 days resulted in significant reduction in serum testosterone (Latif et al, 2008) and spermatogenesis (Latif et al, 2009).

By and large, serum testosterone levels are regulated through the hypothalamic-pituitary-testicular axis. Therefore, suppression in serum testosterone levels with the use of amlodipine indicates either a direct action of this compound on testes, affecting testosterone synthesis at the Leydig cell level, or an indirect action affecting the hormonal milieu at the level of the hypothalamic-pituitary axis.

Department of Physiology, College of Medicine, University of Dammam, Dammam, Saudi Arabia

Address for correspondence: R. Latif, Dr, Department of Physiology, College of Medicine, University of Dammam, Dammam, Saudi Arabia. Phone: +966.0596 .212648$

Acknowledgement: The author acknowledges the financial support of Higher Education Pakistan for this research.
Calcium is implicated in the regulation of different pituitary hormones. There is evidence that many calcium channel blockers like verapamil, diltiazem, nifedipine and lacidipine interfere with secretion of pituitary hormones such as prolactin and folliclestimulating hormone (FSH) (Ridefelt et al, 1996, Romeo et al, 1996). Calcium acts as a second messenger in GnRH mechanism of action, stimulating both gonadotropin secretion as well as gonadotropin gene expression (Haisenleder, 2001, Vasilyev, 2002). The Calmodulin (downstream third messenger) has been proposed to pass on $\mathrm{GnRH}$-induced calcium signals to the gonadotropin subunit genes (Haisenleder, 2003). Therefore it is logical to predict that a blockade of calcium entry would alter the pituitary gonadotropins secretion. Thus, the present study was designed and carried out to observe the effects of amlodipine on pituitary gonadotropins in adult rats.

\section{Material and methods}

\section{Ethical approval}

The Committee for Postgraduate Studies, Army Medical College approved the project and relevant regulations governing the study.

The study was conducted at the Department of Physiology, Army Medical College, National University of Sciences and Technology, Islamabad from 2009-2010. It was an experimental study in which 60 adult male Sprague Dawley rats (age 90-120 days, body weight $170 \pm 50 \mathrm{~g}$ ) were included. The animals were acclimatized for about a week in the same room in which they were 


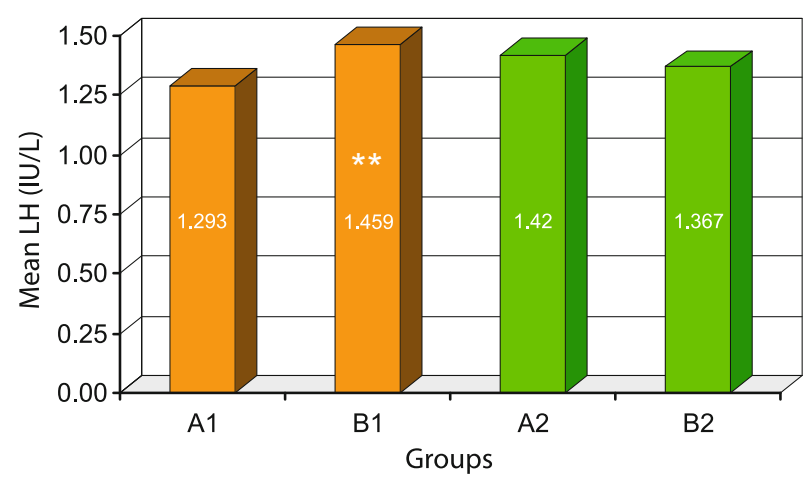

Fig. 1. Mean LH in all groups of rats. Key: A1 - control, B1 - amlodipine-treated, A2 - control recovery, B2 - amlodipine recovery, ${ }^{* *} \mathrm{~A} 1$ vs $B 1$ p $<.01$, A2 vs B2 $p>0.05$. Error bars: \pm 1.00 standard error.

housed for the study. Later, the animals were randomized and assigned to two groups as follows.

\section{Group A}

This group served as a control for group B. It consisted of 30 rats which were further subdivided equally into group A1 (control) and A2 (control recovery). All rats in group A were orally given vehicle ( $0.5 \mathrm{ml}$ distilled water) daily for 50 days. After that, group A1 rats were sacrificed while group A2 rats were kept for recovery and sacrificed after another 50 days.

\section{Group B}

This group also consisted of 30 rats which were further subdivided into group B1 (amlodipine-treated) and B2 (amlodipine recovery). All rats in group B were given amlodipine orally in a dose of $0.14 \mathrm{mg} / \mathrm{kg} / 0.5 \mathrm{ml} / \mathrm{rat}$, daily for 50 days. Group B1 rats were sacrificed 24 hours later after the last experimental day, while the other half (B2) was sacrificed after another 50 days.

Throughout the study period, food and tap water were provided ad libitum. The rooms were maintained at $22 \pm 3^{\circ} \mathrm{C}, 50-60 \%$ relative humidity, 12-hour light/dark period, and 10-15 air changes per hour. Body weights and food consumption were recorded weekly in both groups. All animals were observed twice daily for signs of toxicity, morbidity, or mortality.

\section{Administration of drug}

Amlodipine in dose of $0.14 \mathrm{mg} / \mathrm{kg} /$ day was given with the help of a gavage tube. The initial average body weight of the animals was $170 \pm 50 \mathrm{~g}$ but the animals were treated with amlodipine for long periods of time ( 50 days). During treatment the animals were growing and gaining weight, so we weighed the animals weekly and adjusted the dose each time.

\section{Blood sampling}

The animals to be sacrificed were killed by an overdose of ether anesthesia and 3-5 $\mathrm{ml}$ blood was drawn directly from the heart. Samples were centrifuged and serum was kept frozen at $-80^{\circ} \mathrm{C}$ for Enzyme Immunoassays (EIAs) for the quantitative measurement of rat LH and FSH. The absorbance values of different samples from different groups of animals were taken at the same time.

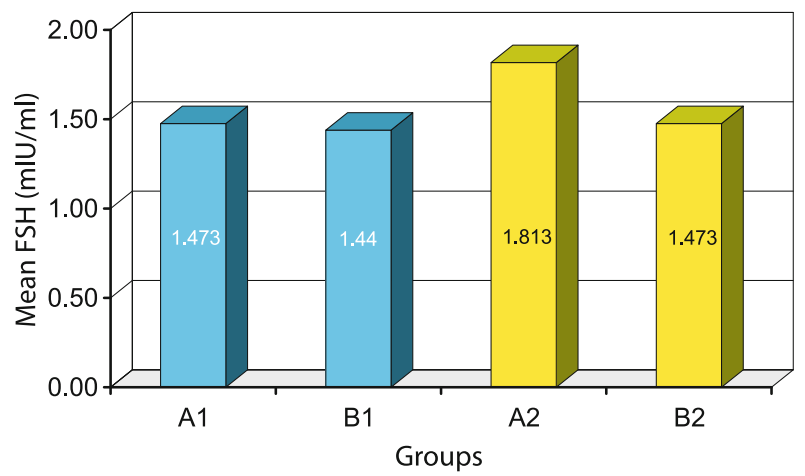

Fig. 2. Mean FSH in all groups of rats. Key: A1 - control, B1 - amlodipine-treated, A2 - control recovery, B2 - amlodipine recovery, A1 vs B1 $p>0.05$, A2 vs B2 $p>0.05$. Error bars: \pm 1.00 standard error.

\section{Measurement of serum $\mathrm{LH}$ and FSH}

Serum LH and FSH were measured by Enzyme immunoassays (EIA). LH and FSH EIA kits were obtained from Alpco Diagnostics and IBL America, respectively. Standard curves were constructed by plotting the mean absorbance obtained from calibrators on Yaxis against their concentrations on $\mathrm{X}$-axis. Using the mean absorbance value for each sample, the corresponding concentration of $\mathrm{LH}$ and FSH were determined from the standard curves.

\section{Statistical analysis}

Statistical analysis was performed using the software package SPSS 13.0 for Windows. Differences between mean values of two groups were evaluated by independent student $\mathrm{T}$ test. Differences were considered significant once the probability value ( $p$ ) was less than or equal to $0.05(\mathrm{p} \leq 0.05)$.

\section{Results}

\section{Serum $L H$}

Serum LH levels were significantly raised in amlodipine-treated group when compared with control. Difference in serum LH of amlodipine recovery and control recovery groups was statistically insignificant (Fig. 1).

\section{Serum FSH}

Amlodipine failed to cause any significant effect in amlodipine-treated and amlodipine recovery groups (Fig. 2).

\section{Discussion}

Mean serum LH levels were significantly raised in group B1 (amlodipine-treated) when compared with group A1 (control). This indicates that long-term amlodipine administration has resulted in increase in synthesis and release of pituitary LH. This is in contrast to the study available in literature that has shown either reduction (Stojilkovic, 1988) or no effect (Semple, 1984) on serum gonadotropins upon the use of CCBs. The exact cause of this discrepancy in results is not known but that could be due to the difference in class of CCB being used, duration of exposure, animal species used, or technique used to measure serum gonado- 
tropins. Most of the studies documenting a decrease in pituitary gonadotropin release upon CCB are based on in vitro experiments. Contrary to that, we have measured serum gonadotropins in vivo. This may render more reliability to our results. Our results even did not match the study conducted by Almaida who used the same drug and same species of rats as those used in the study presented herein (Almaida et al, 2000). Almaida showed no effects on serum LH with oral amlodipine treatment. The reason behind the difference between our results and those of Almaida could be due to the difference in duration of drug administration as we were giving amlodipine for 50 days whereas Almaida was giving it for 30 days.

One of the possibilities is that amlodipine may have had a direct stimulatory effect on hypothalamic GnRH and the increased GnRH might have caused an increase in serum LH levels. Had it been true, serum FSH levels would have also been raised along with LH and increased LH would have resulted in increased serum testosterone levels, but serum FSH levels were not significantly raised in B1 (amlodipine-treated) group and we have previously shown that testosterone levels were significantly reduced in experimental groups ((Latif et al, 2008). Moreover, literature also reports a reduction in serum GnRH with use of CCBs (Leclerc and Boockfor, 2007). So, this explanation is ruled out. Nevertheless, another possibility of our results might lie in the reduction in steroid negative feedback signals (3) which led to a compensatory increase in serum LH.

ThedifferencebetweenmeanserumFSHandLHlevels ofB2 (amlodipine recovery) and A2 (recovery control) groups was statistically insignificant. This indicates that the increase in serum LH induced by amlodipine administration in rats was reversible and abolished at the end of 50-day drug withdrawal period. This is in agreement with literature stating that adverse effects of CCBs are reversible in nature.

The difference between serum FSH of B1 (amlodipine-treated) and A1 (control) group was non-significant, indicating no effect of amlodipine on serum FSH levels. This is in contrast to our expectations. We expected a rise in serum FSH due to two reasons as follows.

Firstly, major feedback regulators of FSH are estradiol and inhibin. Serum inhibin has been positively correlated with serum testosterone (El Garem et al, 2002). We have already shown a reduction in testosterone upon amlodipine (Latif et al, 2008). There is a possibility that this lack of testosterone either may directly affect Sertoli cell production of inhibin (Hayes et al, 2001) or, alternatively, may interfere with spermatogenesis and thus with paracrine regulation of inhibin by germ cells (Depuydt et al, 1999, Foresta et al, 1999) resulting in decreased inhibin and increased FSH.

Secondly, the aromatase enzyme which converts testosterone into estradiol is calcium-dependent (Benninghoff and Thomas, 2005). Therefore we anticipated that suppressed aromatase activity due to the decrease in calcium during the period of amlodipine administration would lead to a decrease in estradiol levels resulting in increase in serum FSH.

Apparently, we are unable to explain and justify the normalcy of serum FSH with 50-day amlodipine administration but our result strongly favors the study conducted by Semple et al who has reported that the use of CCB has no effect on serum FSH (Semple et al, 1984). However, this is contrary to data of Almaida et al who have shown a decrease in FSH level upon the use of amlodipine (Almaida et al, 2000).
Collectively, our results strongly point towards a reversible increase in serum LH and no effect on serum FSH after amlodipine administration. These results rule out the possibility of decreased pituitary gonadotropins being the cause behind antireproductive effects of amlodipine, hence it is necessary to observe the direct effects of amlodipine on isolated and purified pituitary gonadotrophs.

\section{References}

1. Almaida SA, Teofilo JM, Franci JAA, Brentegani LG, Carvalho TLL. Antireproductive effects of calcium channel blocker Amlodipine in male rats. Exp Toxicol Pathol 2000; 52 (4): 353-356.

2. Benninghoff AD, Thomas $\mathbf{P}$. Involvement of calcium and calmodulin in the regulation of steroidogenesis in Atlantic croaker (Micropogonias undulatus) and modulation by Aroclor 1254. Gen Comp Endocrinol 2005; 144 (3): 211-223.

3. Depuydt CE, Mahmoud AM, Dhooge WS, Schoonjans FA, Comhaire FH. Hormonal regulation of inhibin B secretion by immature rat Sertoli cells in vitro: possible use as a bioassay for estrogen detection. J Androl 1999; 20: 54-62.

4. El Garem YF, El Arini AF, El Beheiry AH, Zeid SA, Comhaire FH. Possible relationship between seminal plasma inhibin $\mathrm{B}$ and spermatogenesis in patients with azoospermia. J Androl 2002; 23 (6): 825-829.

5. Foresta C, Bettella A, Rossato M, La Sala G, De Paoli M, Plebani M. Inhibin B plasma concentrations in oligospermic subjects before and after therapy with follicle stimulating hormone. Hum Reprod 1999; 14: 906-912.

6. Haisenleder DJ, Ferris HA, Shupnik MA. The calcium component of gonadotropin releasing hormone stimulated luteinizing hormone subunit gene transcription is mediated by calcium/calmodulin dependent protein kinase type II. Endocrinology 2003; 144 (6): 2409-2416.

7. Haisenleder DJ, Workman LJ, Burger LL, Aylor KW, Dalkin AC, Marshall JC. Gonadotropin subunit transcriptional responses to calcium signals in the rat: evidence for regulation by pulse frequency. Biol Reprod 2001; 65: 1789-1793.

8. Hayes FJ, DeCruz S, Seminara SB, Boepple P, Crowley WF Jr. Differential regulation of gonadotropin secretion by testosterone in the human male: absence of a negative feedback effect of testosterone on follicle stimulating hormone secretion. J Clin Endocrinol Metab 2001; 86: 53-58.

9. Latif R, Lodhi GM, Aslam M. Effects of amlodipine on serum testosterone, testicular weight and gonado-somatic index in rats. J Ayub Med Coll Abbottabad 2008; 20 (4): 8-10.

10. Latif R, Aslam M, Hussein MM, Butt IF, Mubarik A, Zubair A. Effects of Amlodipine besylate on spermatogenesis in Sprague Dawley rats. Pak Armed Forces Med J 2009; 59 (3): 275-279.

11. Leclerc GM, Boockfor FR. Calcium influx and DREAM protein are required for GnRH gene expression pulse activity. Mol Cell Endocrinol 2007; 267 (1-2): 70-79.

12. Meacham RB. The effect of calcium channel blockers on male reproductive potential. J Androl 2006; 27 (2): 160-165.

13. Ridefelt P, Hellman P, Rasted J. Effects of calcium channel modulators on the regulation of calcium and hormone secretion of parathyroid cells. Pharmacol Toxicol 1996; 78: 147-153.

14. Romeo JH, Dombrowski R, Kwak YS, Fuehrer S, Aron DC. Hyperprolactinaemia and : prevalence and potential association with hypogonadism in men. Clin Endocrinol 1996; 45 (5): 571-575.

15. Semple CG, Thomson JA, Beastall GH, Lorimer AR. Calcium antagonists and endocrine status: lack of effect of oral verapamil on pituitary-testicular and pituitary-thyroid function. Br J Clin Pharmacol 1984; 17: 179-182.

16. Stojilkovic SS, Izumi S, Catt KJ. Participation of Voltage-sensitive Calcium Channels in Pituitary Hormone Release. J Biol Chem 1988; 263 (26): 13054-13061.

17. Vasilyev VV, Lawson MA, Dipaolo D, Webster NJG, Mellon PL. Different signaling pathways control acute induction versus long term repression of LHB transcription by GnRH. Endocrinology 2002; 143 (9): 3414-3426.

Received March 31, 2013. Accepted March 23, 2014. 